$\underline{\text { Avicenna Journal of Nursing and Midwifery Care - ISSN 2676-5748 }}$

\title{
The Effect of Music on Fetus Movement During Non-Stress Test
}

\author{
Batoul Khodakarami ${ }^{1}$, Marzieh Janesari Ladani ${ }^{2}$, Farideh Kazemi ${ }^{3}$, Soudabeh Aghababaei ${ }^{\text {*4 }}$
}

1. Instructor, Mother and Child Care Research Center, Nursing and Midwifery Faculty, Hamadan University of Medical Sciences, Hamadan, Iran

2. MSc Student, Department of Midwifery, School of Nursing and Midwifery, Hamadan University of Medical Sciences, Hamadan, Iran

3. PhD, Department of Midwifery, Mother and Child Care Research Center, Nursing and Midwifery Faculty, Hamadan University of Medical Sciences, Hamadan

4. Assistant Professor, Mother and Child Care Research Center, Nursing and Midwifery Faculty, Hamadan University of Medical Sciences, Hamadan, Iran

\section{Article Info}

Received: 2020/06/13;

Accepted: 2020/09/06;

Published Online: 2020/11/23

10.30699/ajnmc.28.4.1

Original Article

Use your device to scan and read the article online

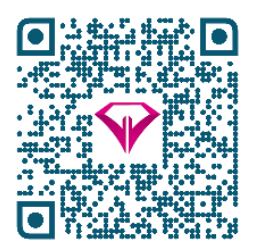

\section{ABSTRACT}

Introduction: To reduce mortality occurrence on the day of birth, it is recommended to evaluate the health of the fetus during pregnancy. The most widely used technique in most centers as the ideal screening for fetal health assessment is non-stress test. Due to the fact that reducing fetal movement is one of the immediate symptoms of fetal death, this study was conducted to determine the effect of music on fetal movement during non-stress test.

Methods: This randomized double-blind clinical trial was performed on 160 first-time pregnant women aged 37-40 weeks who had referred to Fatemieh Hospital in Hamadan, Iran, with a complaint of reduced fetal movement in 2019. Individuals were randomly assigned to two control and experimental groups of 80 . In the experimental group, 30 minutes of intervention was performed by listening to nonverbal music, but in the control group, no intervention was performed. Data analysis was performed using SPSS 20 and Chi-square test, Mann-Whitney U test and T test. P-value $<0.05$ was considered significant.

Results: In the intervention group, the average difference in the number of fetal movements was more than the control group and this difference was significant. It had a significant decrease in the number of non-reactive tests in the intervention group compared to the control group $(P<0.001)$. The number of basal fetal heart in the intervention group decreased significantly compared to the control group $(P=0.01)$.

Conclusion: Music can improve fetal movements and increase the number of reactive tests.

Keywords: Fetal movement, Music, Non-stress test

How to Cite This Article:

Khodakarami B, Janesari Ladani M, Kazemi F, Aghababaei S. The Effect of Music on Fetus Movement During Non-Stress Test. Avicenna J Nurs Midwifery Care. 2020; 28 (4) :1-8 


\section{تأثير موسيقى بر حركت جنين هنگًام آزمون بدون استرس

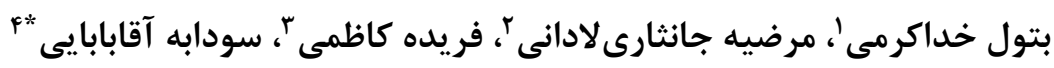

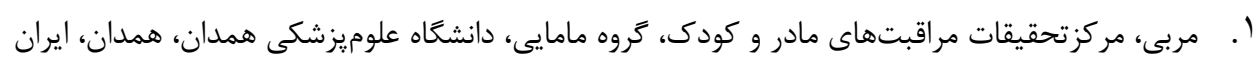

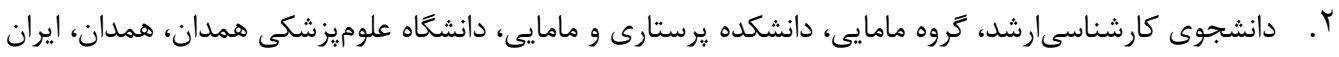

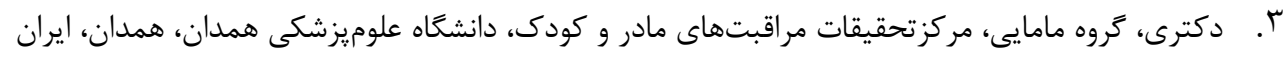

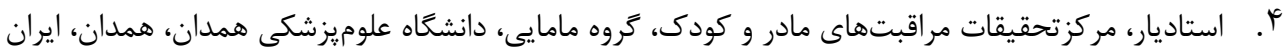

\begin{tabular}{|c|c|}
\hline جكيده & اطلاعات مقاله \\
\hline 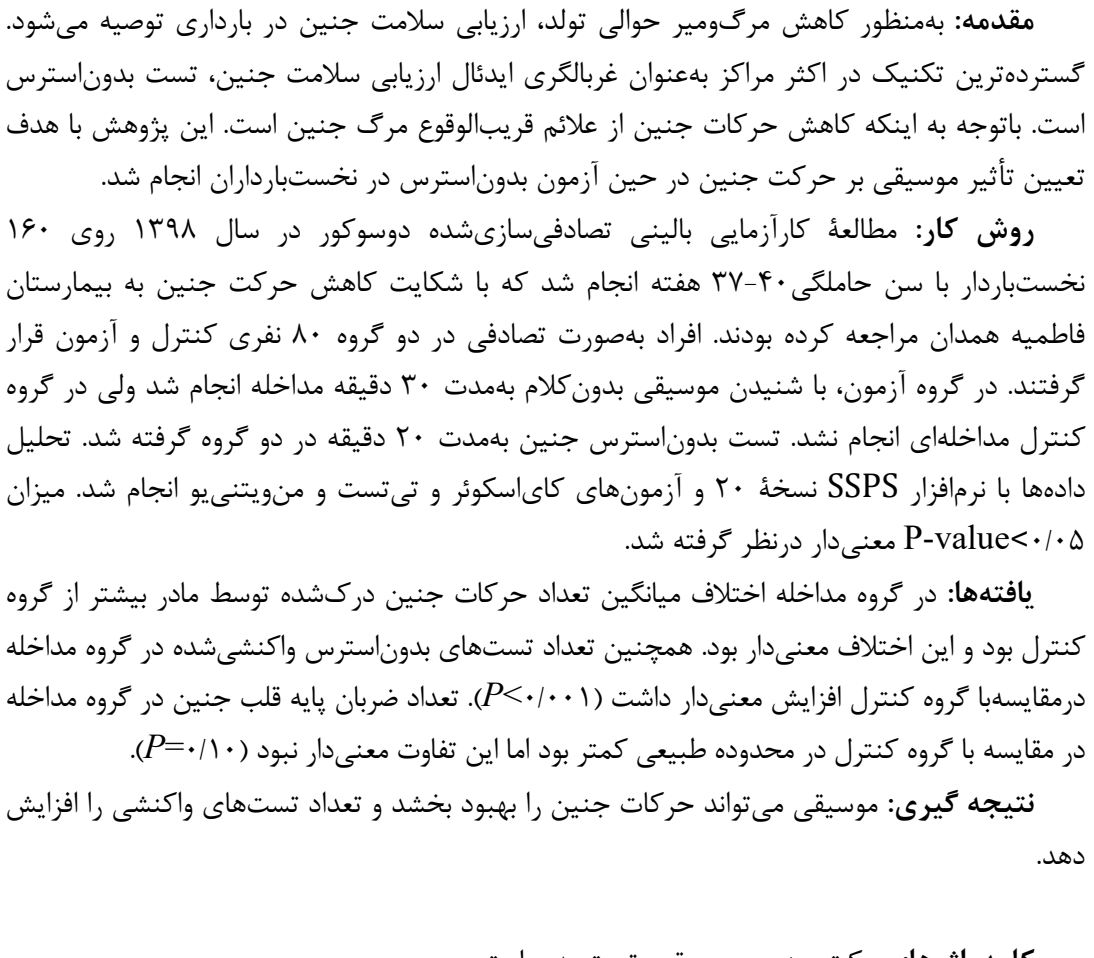 & 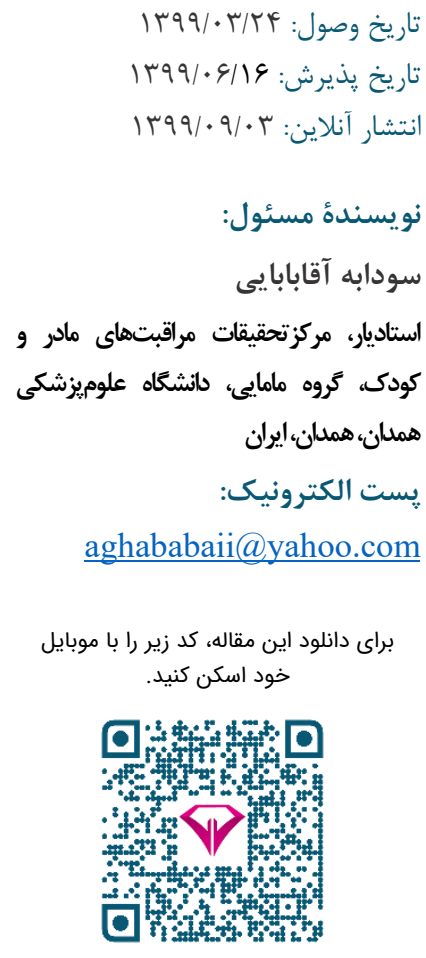 \\
\hline كليدوازهها: حركت جنين، موسيقى، تست بدوناسترس & \\
\hline
\end{tabular}

مقدمه

سيعاركشيدن، نوشيدن الكل، مصرف داروهاى آرامبخش،

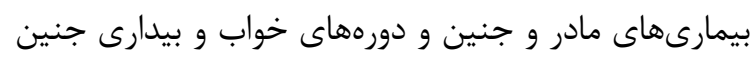

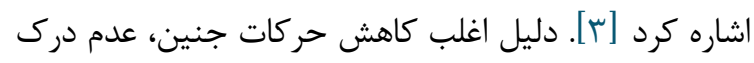

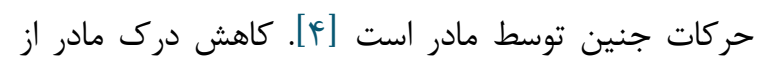

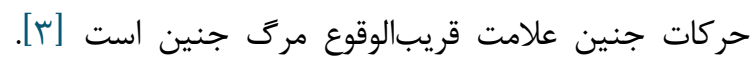
ازآنجاكه بيش از دوسوم مركهاى جنين قبل از تولد به وقوع

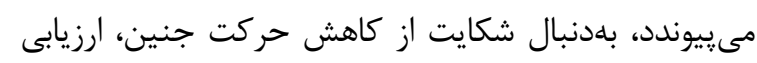
سلامت جنين، بdمنظور كاهش مركومير حوالى تولد توصيه

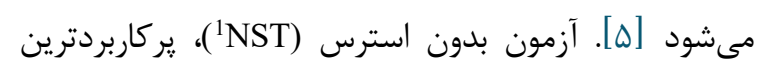

حركات جنين از لرزشهاى ضعيف در اوايل باردارى تا

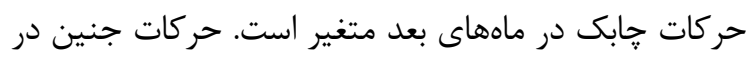

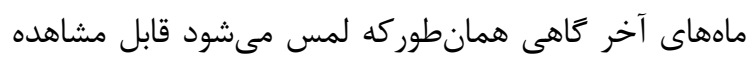

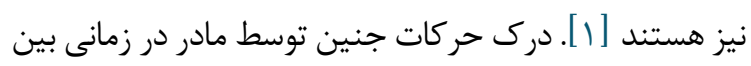

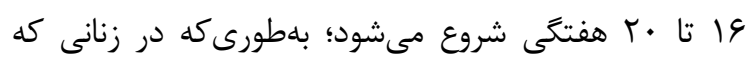

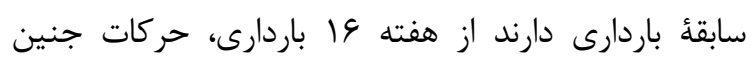

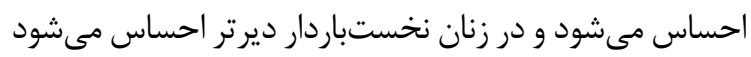
[r]. عوامل متعددى بر حركات جنين تأثير مى گذارد؛ ازجمله

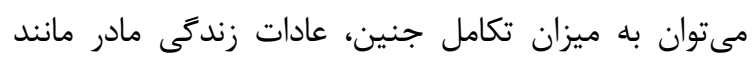

\footnotetext{
${ }^{1}$ Non-Stress Test
} 
نخست باردار با هم مورد بررسى قرار گرفتند در حالى كه براى بررسى حركات جنين نياز به يكسانسازى ازنظر تعداد باردارى ديده شد كه در مطالعات مذكور مورد توجه قرار

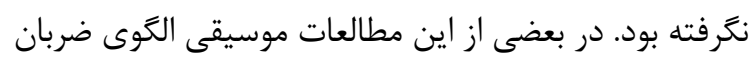

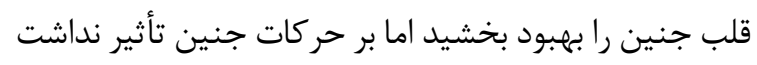

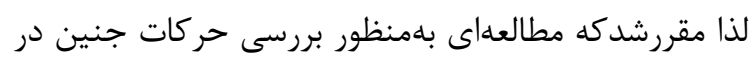

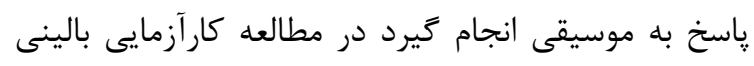

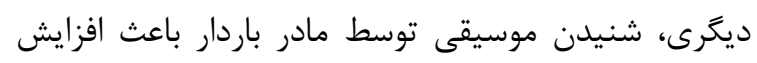

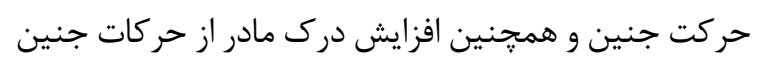

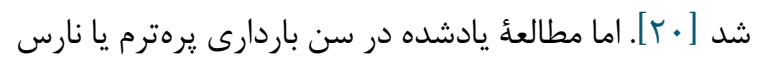

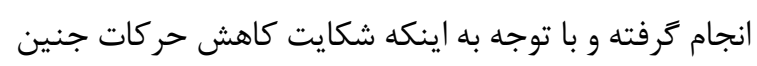

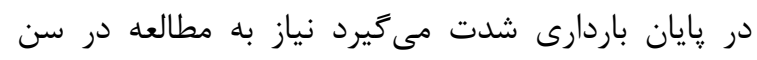
باردارى بالاتر در اواخر باردارى بود بارد ديرد

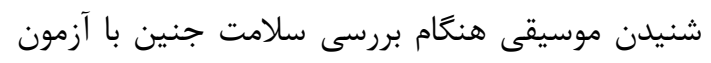
إناستى، درعين صرفهجويى در وقت و هزينه و نيروى انسانى سنى

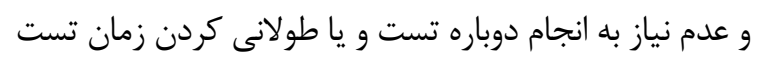

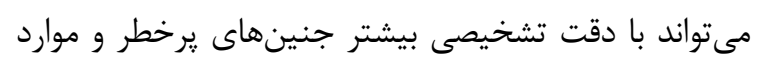

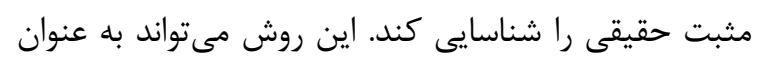

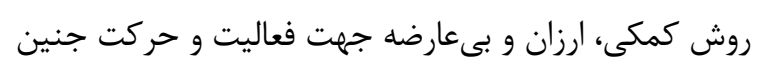

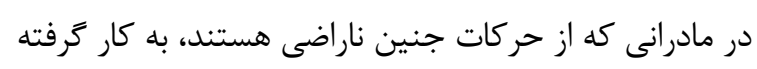

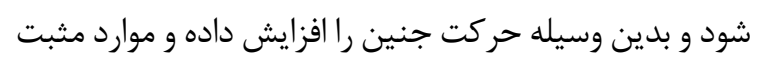

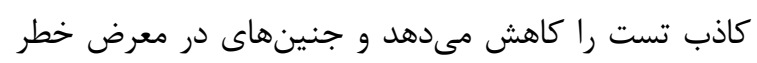
واقعى را بهتر شناسايى مى كند. كاهث مهد و

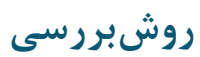

مطالعهُ حاضر از نوع كارآزمايى بالينى از گروههاى مداخله

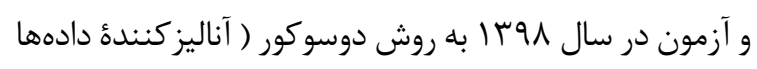

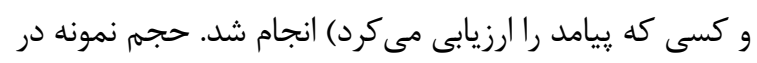

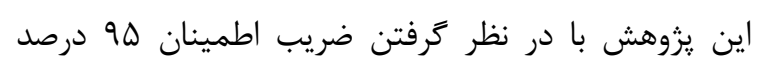

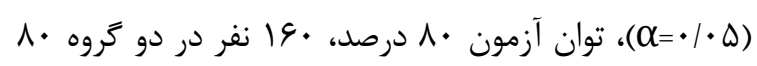
نفرى در نظر كرفته شد.

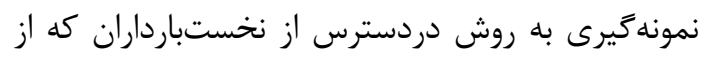

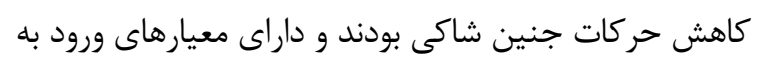

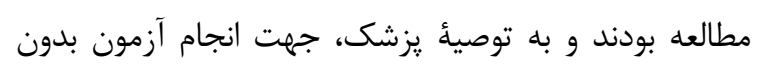

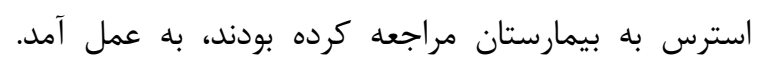
نمونهكيرى در شيفت صبح در اورزانس مامايى بيمارستان

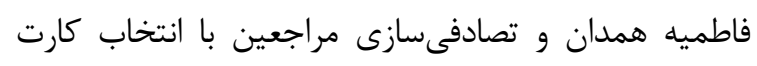

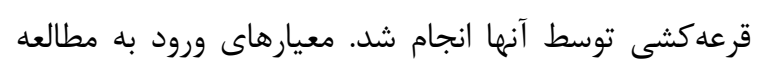

روش اوليه در ارزيابى جنين در همه جوامع است. از مزاياى

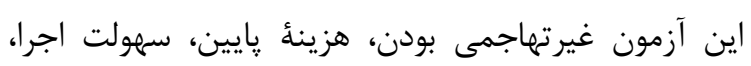

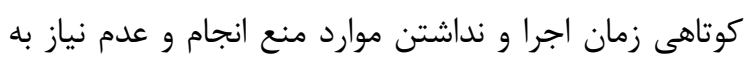

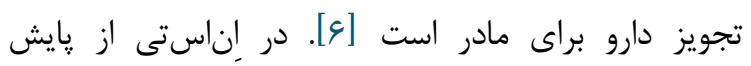
الكترونيكى براى ثبت ضربان قلب جنين استفاده مىشود. وقتى تسريع كذراى ضربان قلب جنين اتفاق مىافتد جنين إنين

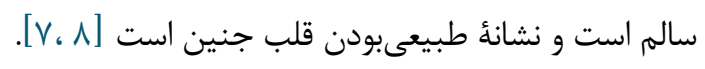

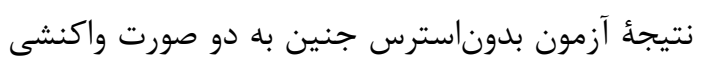

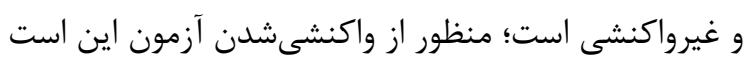

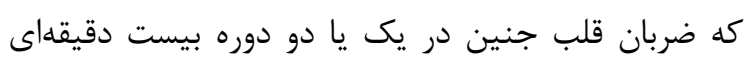

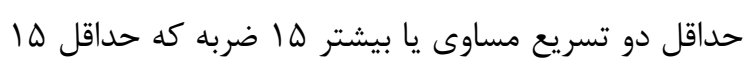

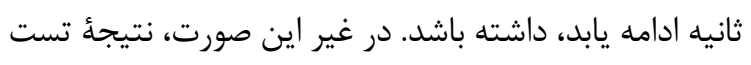

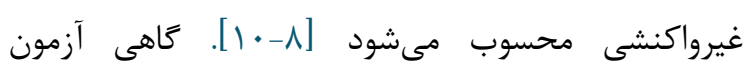
بدوناسترس نتايج غيرطبيعى كاذب دارد ولى ولى بيشى بيشتر

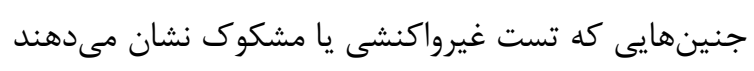

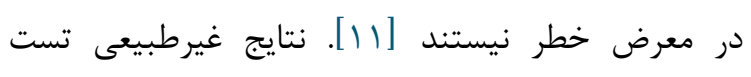
بدوناسترس ممكن است در جنينهاى در حال خواب ديده نئن

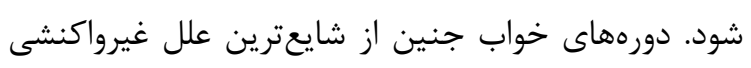

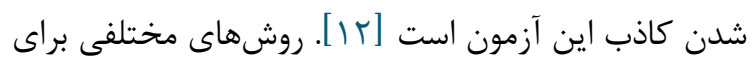

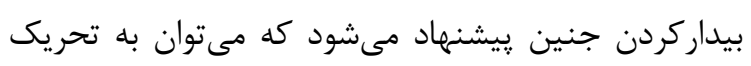
صوتى جنين، شنيدن موسيقى، تغيير وضعيت مادر، تحريك

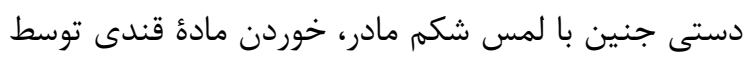
مادر اشاره كرد [1 ا1]].

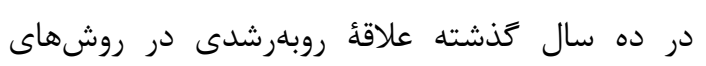
غيردارويى براى رفع بسيارى از اختلالات باردارى مشاهده

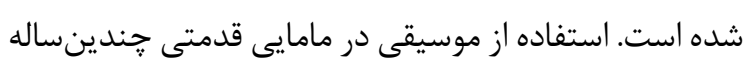

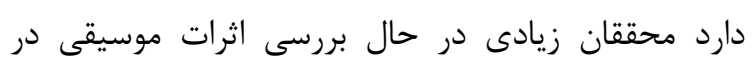

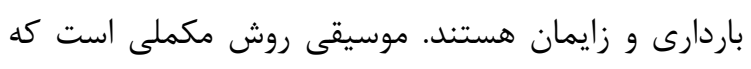

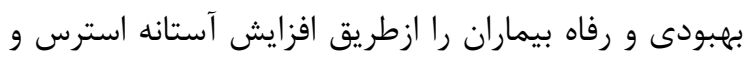

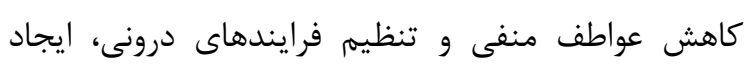

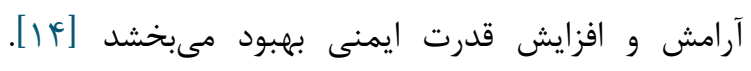

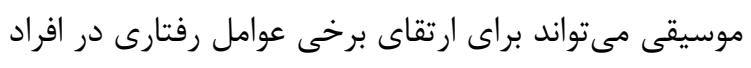

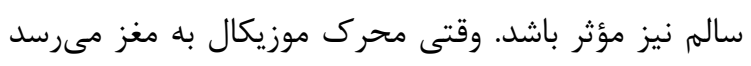

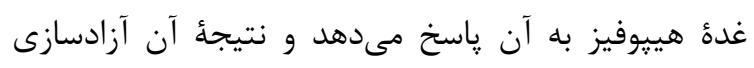

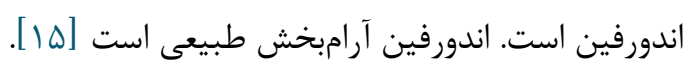

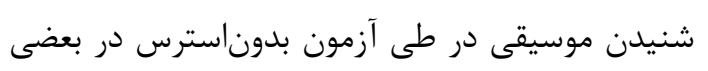

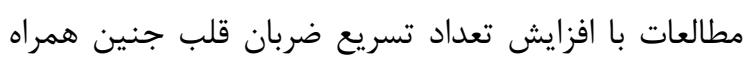

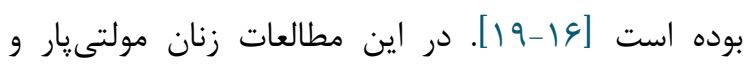


يكسانسازى بيشتر براى همأ افراد از يك دستخاه ارزيابى

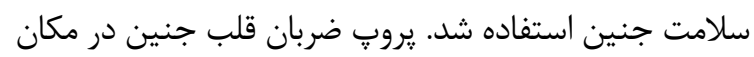

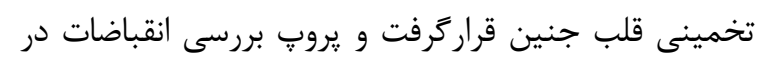

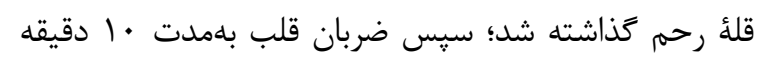

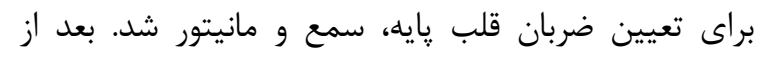

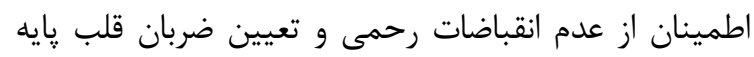

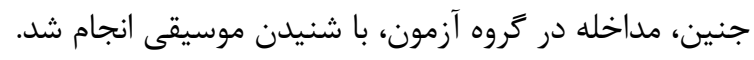

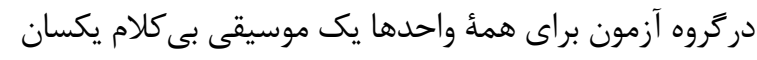

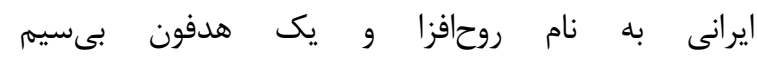
بلوتوث-HS940BTXP استفاده شد. شنيدن موسيقى در گروه

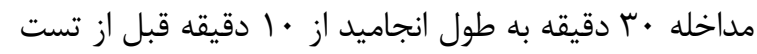

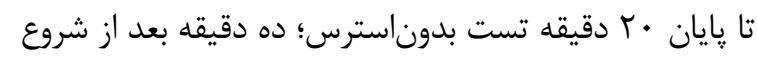

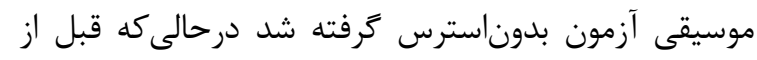

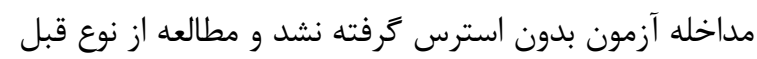

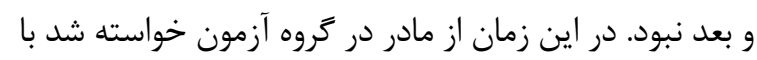
هر حركت جنين كه حس كند يك برش بر كاغذى بز بزند كه إنه

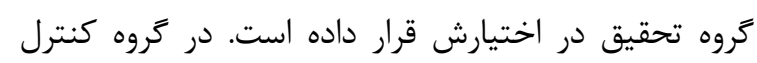

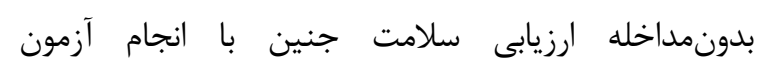

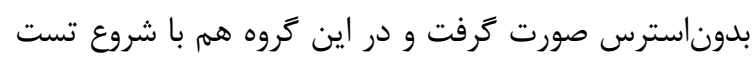

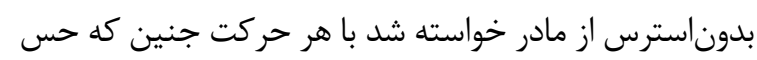
كرد برشى بر كاغذى كه گروه تحقيق در اختيارش قرار دادئه

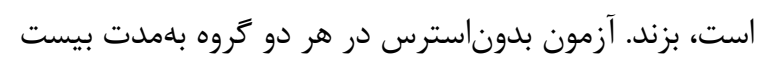

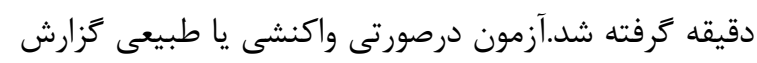

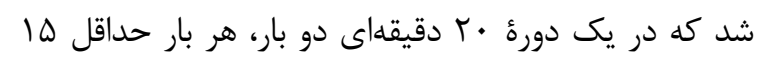

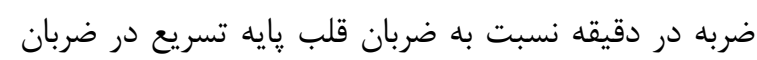

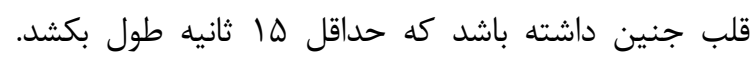
درصورت عدم تسريع ضربان قلب بلهصورتى كه توضيح داده

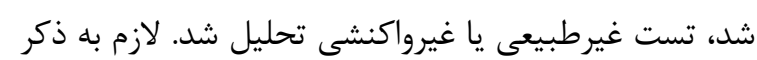
است كه ريزش نمونه وجود نداشت.

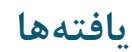

براساس نتايج، ميانكَين سنى مادران در كروه مداخله

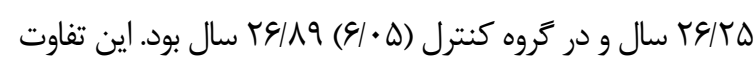

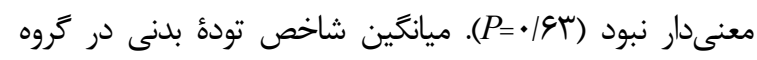

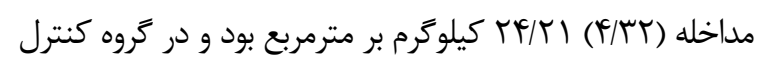
(Y/MA)

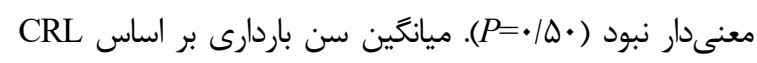

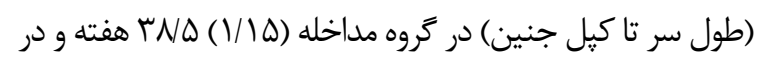

عبارت بودند از شكايت مادران نخستباردار از كاهش حركت

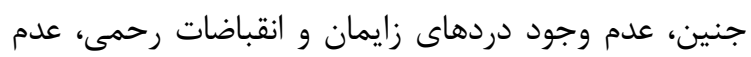

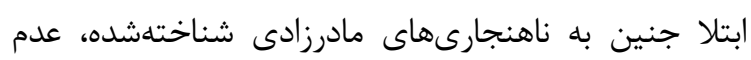

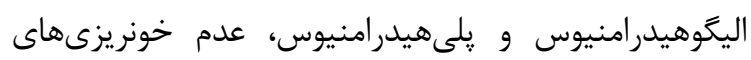

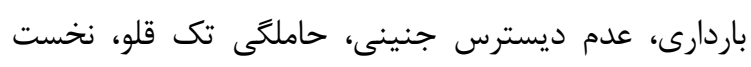

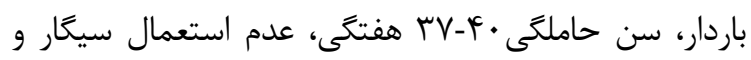

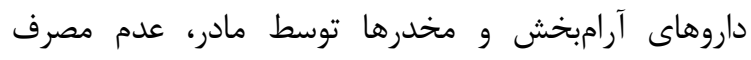

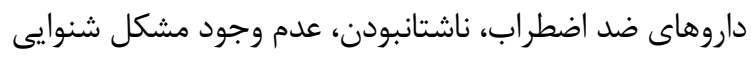

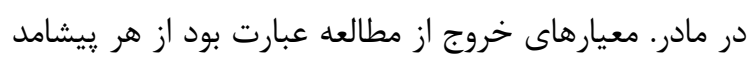

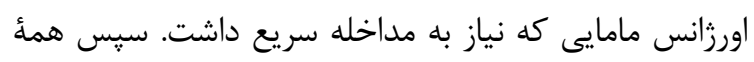

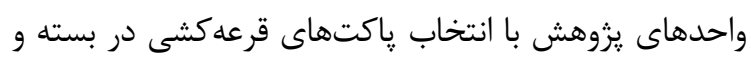

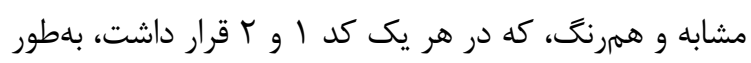

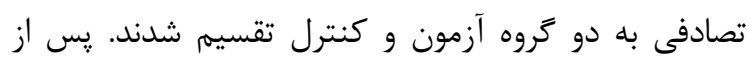

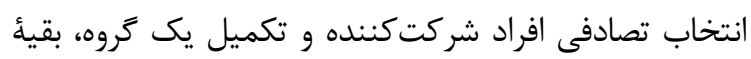
شركت كنندكان در كروه ديخر قرار كرفتند. فرم ثبت اطلاعات

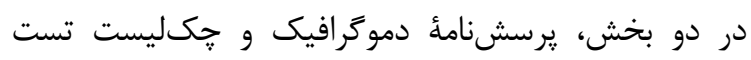
بدوناسترس طراحى شد وسيس تعيين روايى اين فرم به درنه

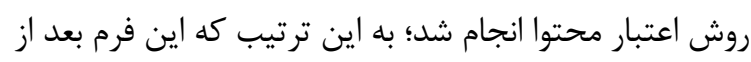

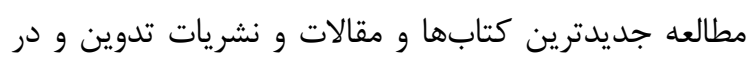

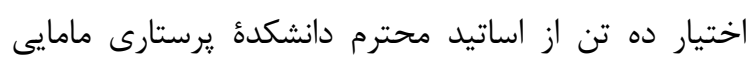

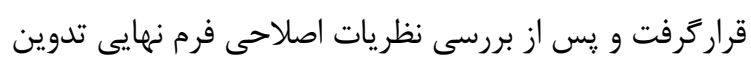

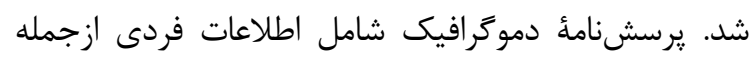
سن، تحصيلات فرد وهمسرش، شغل فرد و شغل همسرش،

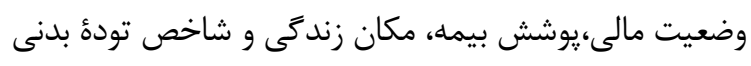
بود و اطلاعات مربوط به تست بدوناسترس جنين ازئه ازجمله

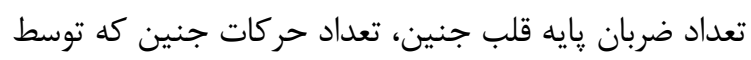

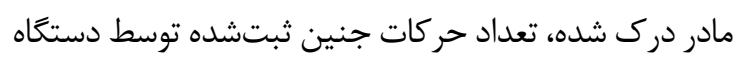

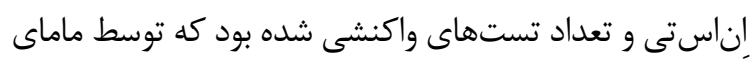

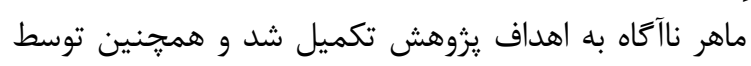

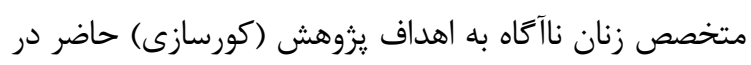
بيمارستان تأييد شد. حركات جنين توسط مادر طاه بـ آز آزمون

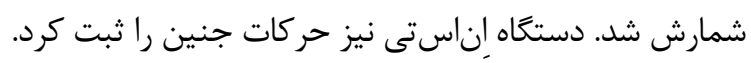

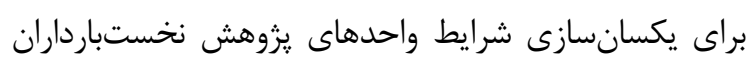

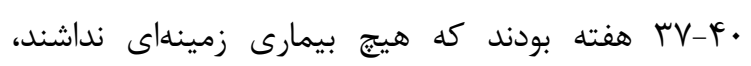

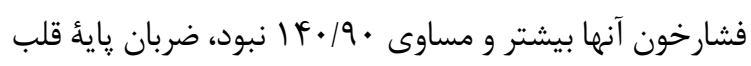

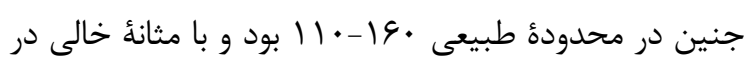

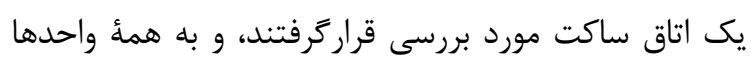

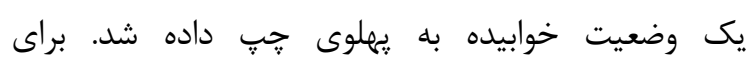


تعداد حركت جنين كه توسط مادر درك شده، در گروه

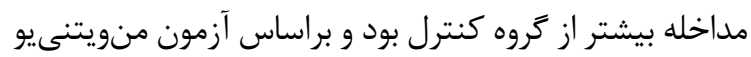

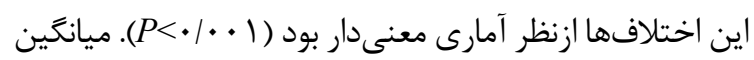

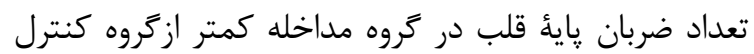

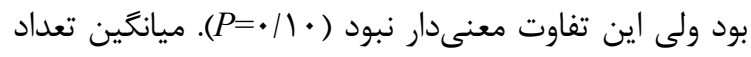

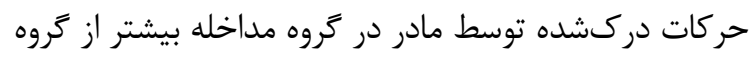

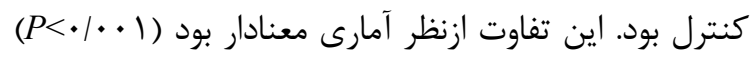
(جدول r). نتايج جدول r نشان داد اكثريت تستها در گروه مداخله

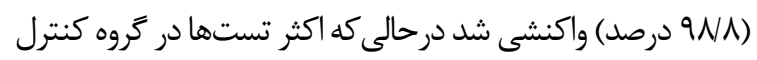

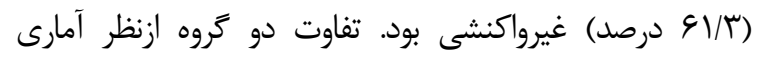

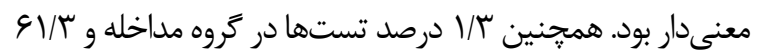

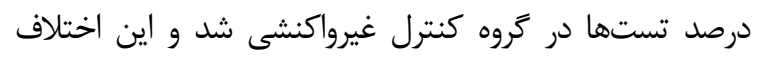

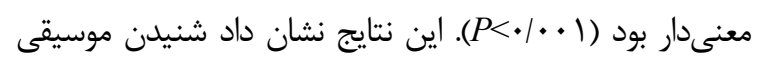

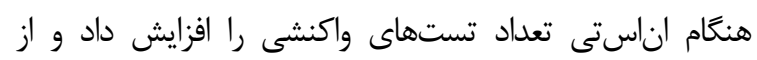

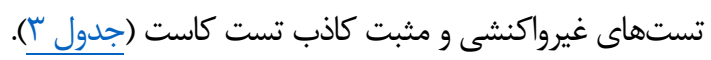

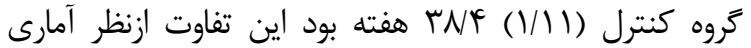
معنى دار نبود (P=/V9). طبق جدول انتايج نشان داد اكثريت مادران در هر كروه مداخله و كنترل داراى تحصيلات دييلم بودند. اكثر همسر ان در دو كروه مداخله و كنترل داراى تحصيلات دييلم بودند.

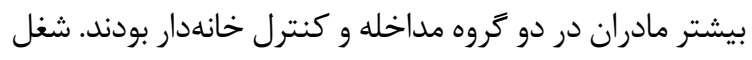

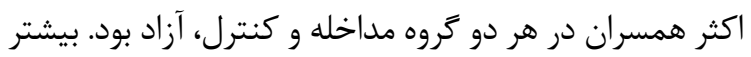

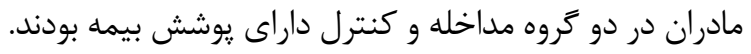

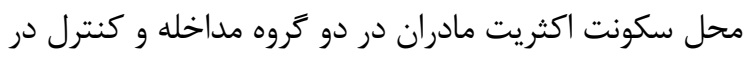

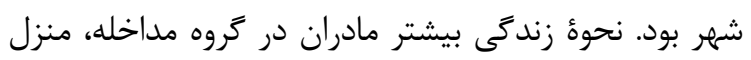

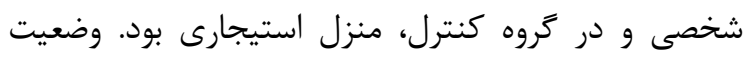

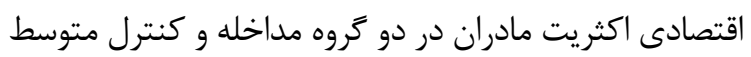

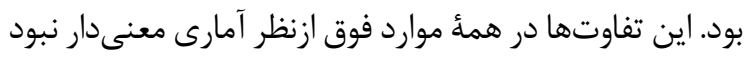

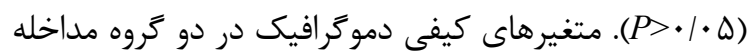

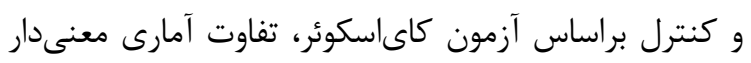
نداشت و دو تروه ازنظر اين متغيرها همسان بودند (جدول كاني (1).

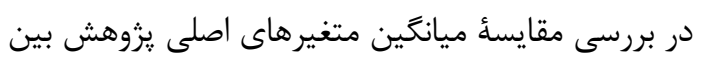

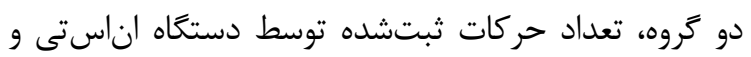

جدول ا. مقايسهُ متغيرهاى كيفى دموكَرافيك در دو كَروه مداخله و كنترل براساس آزمون كاىاسكوئر

\begin{tabular}{|c|c|c|c|c|c|c|}
\hline \multirow[t]{2}{*}{$P$} & \multicolumn{2}{|c|}{$\begin{array}{l}\text { كنترل } \\
N=\Lambda .\end{array}$} & \multicolumn{2}{|c|}{$\begin{array}{l}\text { مداخله } \\
\mathrm{N}=1 \text {. }\end{array}$} & \multirow[t]{2}{*}{ تروه } & \multirow{2}{*}{ متغير } \\
\hline & درصد & تعداد & درصد & تعداد & & \\
\hline \multirow{2}{*}{$\cdot / \Delta V$} & $9 r / 0$ & ve & $9 \cdot 1 \cdot$ & VT & خانهدار & \multirow{2}{*}{ شغل مادر } \\
\hline & $V / \Delta$ & 4 & $1 \cdot \%$ & $\wedge$ & كارمند & \\
\hline \multirow{4}{*}{$\cdot / \Lambda}$. & $\Lambda / \Lambda$ & V & $V / \Delta$ & 9 & بيكار & \multirow{4}{*}{ شغل همسر } \\
\hline & 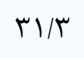 & ro & $r V / Q$ & $r$. & كارتر & \\
\hline & $r / \Delta$ & $r$ & $\mathrm{r} / \Lambda$ & r & كارمند & \\
\hline & $\Delta V / \Delta$ & is & $\Delta 1 / \mu$ & i) & آزاد & \\
\hline \multirow{4}{*}{.1 .9} & $\cdot /$ & . & $1 / \mu$ & 1 & بىسواد & \multirow{4}{*}{ تحصيلات } \\
\hline & TN/A & r & $r \cdot 1 \cdot$ & rT & زيردييلم & \\
\hline & $q \pi / \Lambda$ & $\Delta 1$ & $\forall \Delta / \cdot$ & re & دييلم & \\
\hline & $V / Q$ & 4 & $\mid r / \Lambda$ & 11 & دانشخاهى & \\
\hline \multirow{4}{*}{ سא/. } & $\cdot 1 \cdot$ & . & $1 / \mu$ & 1 & بـىسواد & \multirow{4}{*}{ تحصيلات } \\
\hline & $F \Delta / \cdot$ & rq & $F \Delta / \cdot$ & re & زيردييلم & \\
\hline & $\Delta r / \Delta$ & Fr & $\varphi g / \pi$ & rV & دييلم & \\
\hline & $r / Q$ & r & $V / Q$ & 4 & دانشخاهى & \\
\hline \multirow{2}{*}{ צ/r/ } & $99 / T$ & VG & $91 / 1$ & vq & دارد & \multirow{2}{*}{ يوشش بيمه } \\
\hline & $\mathrm{r} / \Lambda$ & r & $1 / r$ & 1 & ندارد & \\
\hline$\cdot / \Lambda V$ & $k \cdot 1 \cdot$ & rt & $|F| / r$ & rr & روستا & محل زندگى \\
\hline
\end{tabular}




\begin{tabular}{|c|c|c|c|c|c|c|}
\hline \multirow[t]{2}{*}{$P$} & \multicolumn{2}{|c|}{$\begin{array}{l}\text { كنترل } \\
N=\Lambda .\end{array}$} & \multicolumn{2}{|c|}{$\begin{array}{l}\text { مداخله } \\
\text { N=A }\end{array}$} & \multirow[t]{2}{*}{ تروه } & \multirow{2}{*}{ متغير } \\
\hline & درصد & تعداد & درصد & تعداد & & \\
\hline & $4 \cdot 1 \cdot$ & $\psi_{1}$ & $\Delta \Lambda / \Lambda$ & qV & شهر & \multirow{4}{*}{ نحوهُ زندگى } \\
\hline \multirow{3}{*}{. } & $|y| / \Lambda$ & rr & $r \cdot / q$ & TF & استيجارى & \\
\hline & $19 / \cdot$ & rI & $Y N / 1$ & ru & شخصى & \\
\hline & $19 / \cdot$ & 10 & $r M / Q$ & IV & همراه خانواده & \\
\hline \multirow{3}{*}{$\cdot / V V$} & $r \cdot / \cdot$ & TF & $r F / r$ & TV & ضعيف & \multirow{3}{*}{ خانتوادى وضعيت } \\
\hline & $\Delta V / \Delta$ & is & $\Delta 1 / 9$ & (i) & متوسط & \\
\hline & $1 T / \Delta$ & 1. & $1 \% / 9$ & 11 & خوب & \\
\hline
\end{tabular}

جدول r. مقايسةُ ميانعين متغير هاىNST بين دو تروه مداخله و كنترل براساس آزمون منويتنىيو

\begin{tabular}{|c|c|c|c|c|c|c|}
\hline \multirow{2}{*}{$P$} & \multirow{2}{*}{ آماره آزمون } & \multicolumn{2}{|c|}{$\begin{array}{l}\text { كنترل } \\
N=\Lambda\end{array}$} & \multicolumn{2}{|c|}{$\begin{array}{l}\text { مداخله } \\
N=\Lambda\end{array}$} & \multirow{2}{*}{ متغير هاى مSرو مST } \\
\hline & & انحراف معيار & ميانكين & انحراف معيار & ميانغين & \\
\hline$\cdot 11$ & $1 / 9 .-$ & $1 \cdot / 4$ & $1 r q / r \Delta$ & $q / r r$ & $|r G| \Lambda \mid$ & ضربان پايه قلب جنين \\
\hline$\cdot 1 \cdot \cdot 1<$ & $N / G 4-$ & $1 / F V$ & $1 / \cdot 9$ & $r / \cdot V$ & $F / l f$ & تعداد حركات جنين دركشده \\
\hline$\cdot 1 \cdot \cdot 1<$ & $N \cdot \varphi_{-}$ & $1 / 49$ & $1 / \pi$. & $1 / 49$ & 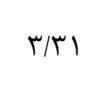 & تعداد حركات جنين ثبتشده \\
\hline
\end{tabular}

جدول س. مقايسةٔ نتيجهُ نهايى NST بين دو حَروه كنترل و آزمون بر اساس آزمون كاىاسكوئر

\begin{tabular}{|c|c|c|c|c|c|c|}
\hline \multirow[t]{2}{*}{$P$} & \multirow[t]{2}{*}{ 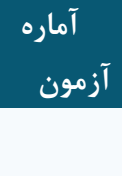 } & \multicolumn{2}{|c|}{$\begin{array}{c}\text { كروه كنترل } \\
\text { N=^. }\end{array}$} & \multicolumn{2}{|c|}{ 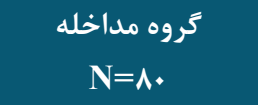 } & نتيجة نهايى \\
\hline & & درصد & تعداد & درصد & تعداد & \\
\hline$<\cdot / \cdot \cdot 1$ & $G \cdot 1 \cdot r \Delta$ & 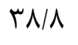 & ri & $91 / 1$ & $\vee 9$ & تست واكنشىشده \\
\hline$<\cdot 1 \cdot \cdot 1$ & & $91 / \pi$ & $4 q$ & $1 / \pi$ & 1 & تست غيرواكنشى \\
\hline
\end{tabular}

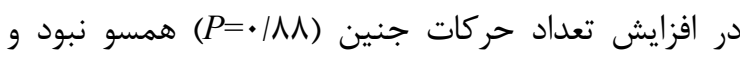

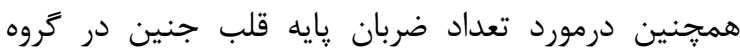
موسيقى درمقايسهبا گروه كنترل افزايش تعداد ضربان پايه

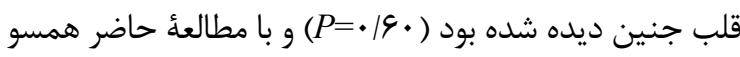

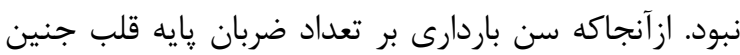

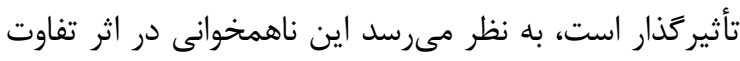

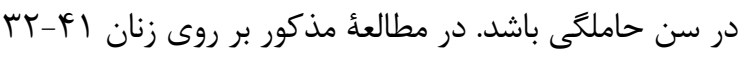

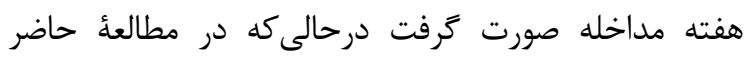

يزوهش حاضر با هدف تأثير موسيقى بر حركات جنين

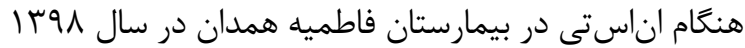
انجام شد. نتايج اين يروهش نشان داد شنيدن موسيقى تعداد

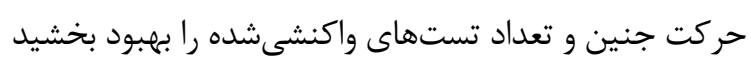
و از تعداد موارد مثبت كاذب تست كاست.

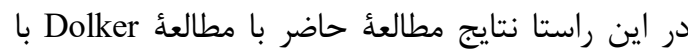
عنوان 》اتثير موسيقى بر اناستى و اضطراب مادرشكه به

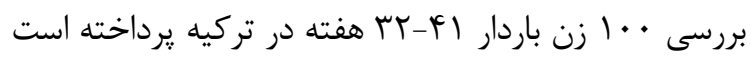




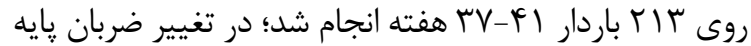

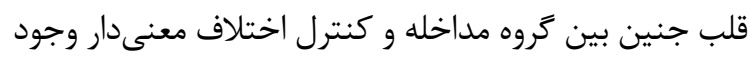

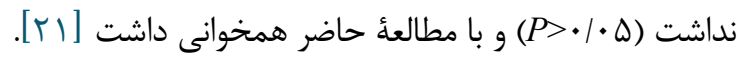

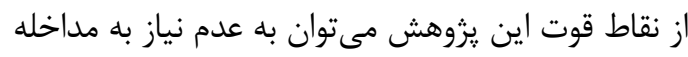

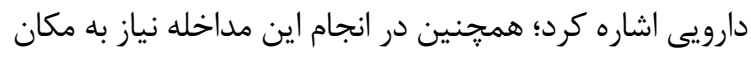
و زمان خاص نيست و نياز به هزينه هم ندارد و مداخلهاي

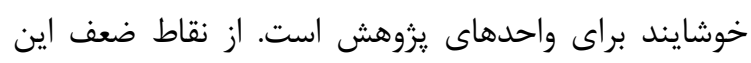
يزوهش مىتوان به عدم مقايسه با قبل از مداخله اشاره كرد

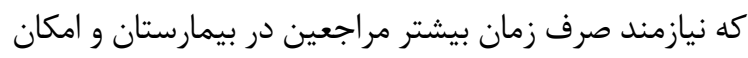

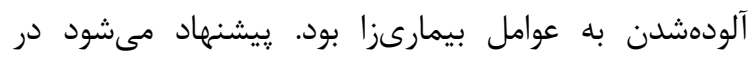

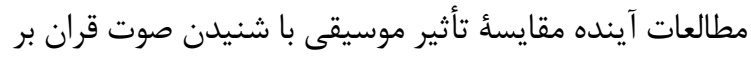

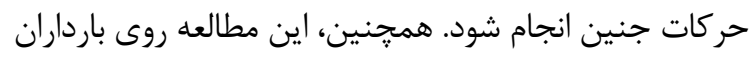

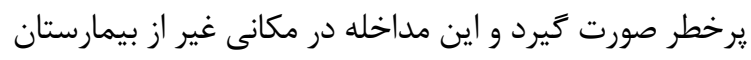

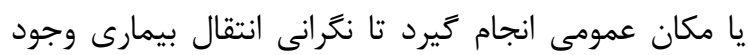

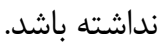

\section{نتيجه "نيرى}

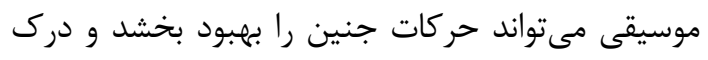

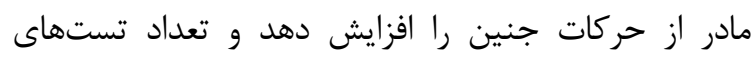
اناستى واكنشىشده را افزايش دهد.

\section{سياسگَزارى}

يزوهش حاضر بخشى از پاياننامه مقطع كارشناسىارشد

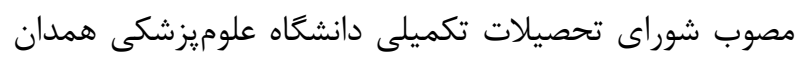
IR.UMSHA است كه در كميته اخلاق با كد اخلاق

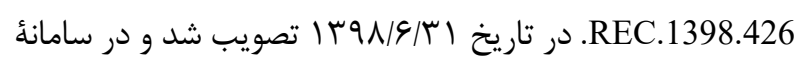
كارآزمايى بالينى با كد شده است. بدين وسيله از اساتيد محترم دانشكده يرستارى

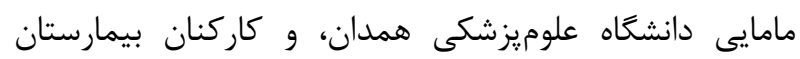

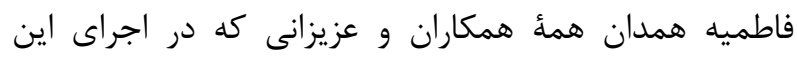
يزوهش شركت نموده و ما را يارى رساندند، تشكر مى كنيم.

\section{تعارض در منافع}

بين نويسندكان هيجَّونه تعارضى در منافع وجود ندارد

$$
\text { منابع مالى }
$$

منابع مالى اين مطالعه توسط نويسندكان تامين شده است.
مداخله روى زنان باردار • • مV-F هفته انجام كرفت. اما ازنظر

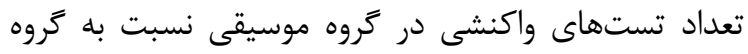

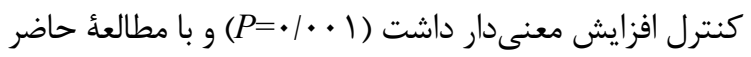

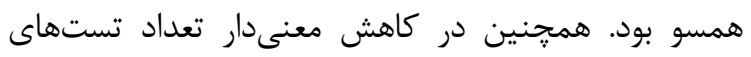
غيرواكنشى در كروه موسيقى در مقايسه با گروه كنترل با دمان

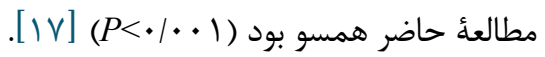
در مطالعُ Pirhadi و همكاران با عنوان لامقايسه تأثير

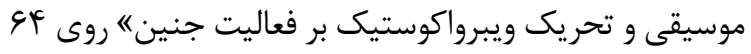

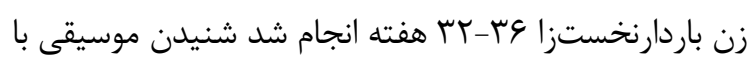
اختلاف معنىدار بيشتر از ويبرواكوستيك باعث افزايش

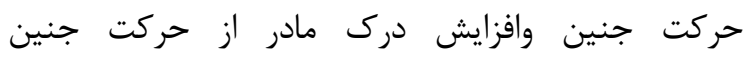

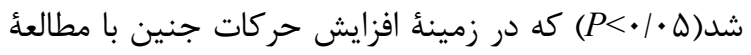

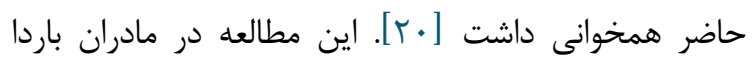

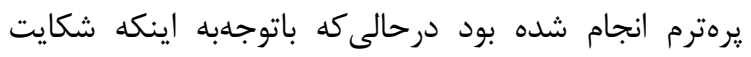

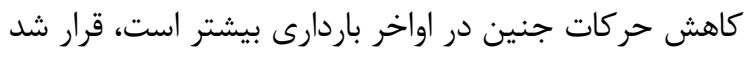

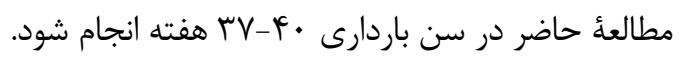

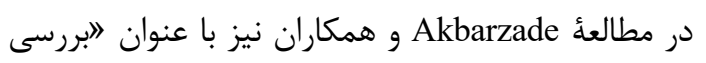

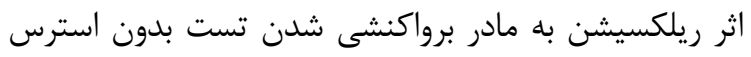

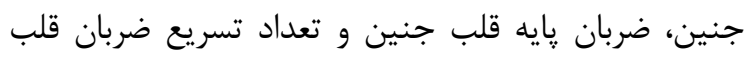

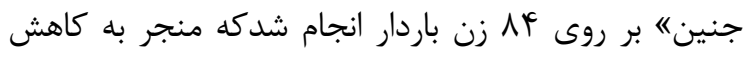

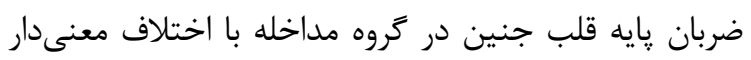

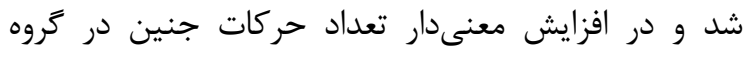

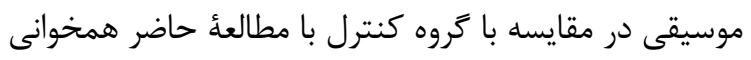

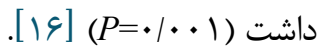
Oh مطالعه كارآزمايى بالينى تصادفى در كره بلوسيله Moh

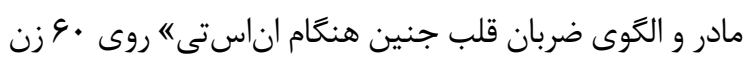

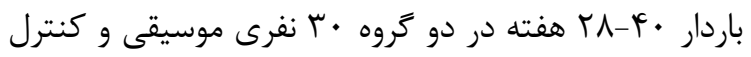

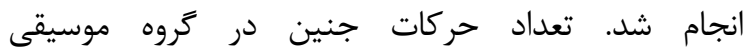

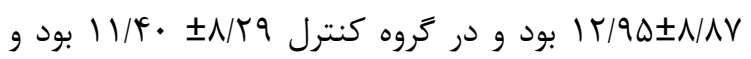
تفاوت معنىدار نبود (Y)/

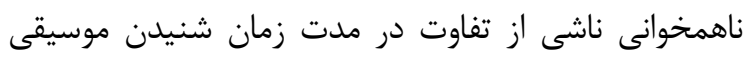

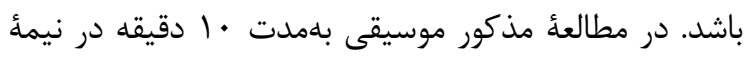

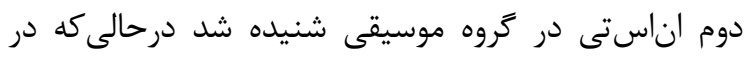
مطالعُ حاضر موسيقى بلمدت · ب دقيقه شنيده شد.

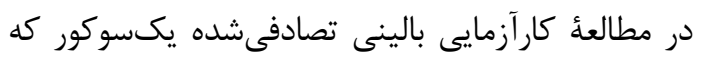
توسط Khoshkholgh و همكاران با عنوان \اتأثير شنيدن موسيقى بهوسيله مادر و جنين بر نتايج اناستى" در شيران 


\section{References}

1. Kamalifard M, Abbasalizadeh S, Ghojazadeh M, Samani FG, Rabiei L. Diagnostic value of fetal movement counting by mother and the optimal recording duration. J Car S. 2013; 2 (2):89.

2. Hijazi ZR, East CE. Factors affecting maternal perception of fetal movement. Obs Gyn Survey. 2009; 64(7):489-97. [DOI:10.1097/OGX.0b013e3181a8237a] [PMID]

3. Brown R, Higgins LE, Johnstone ED, Wijekoon JH, Heazell AE. Maternal perception of fetal movements in late pregnancy is affected by type and duration of fetal movement. J Mat-Fet Neonat Med. 2016; 29(13):2145-50 [DOI:10.3109/14767058.2015.1077509] [PMID]

4. Bradford BF, Cronin RS, McCowan LM, McKinlay CJ, Mitchell EA, Thompson JM. Association between maternally perceived quality and pattern of fetal movements and late stillbirth. Sci Report. 2019; 9(1):1-9. [PMID] [PMCID] [DOI:10.1038/s41598-019-46323-4]

5. Bradford B, Cronin R, McKinlay C, Thompson J, McCowan L. Maternally perceived fetal movement patterns: The influence of body mass index. Early Human Dev. 2020; 140:104922. [DOI:10.1016/j.earlhumdev.2019.104922] [PMID]

6. Kaviani M, Ebadi R, Azima S, Asadi N, Hadianfard M, Sayadi M. The effect of acupressure on non-stress test parameters in primiparous women. Res Obstet Gynecol. 2016; 4(1):1-6.

7. Tan KH, Smyth RM, Wei X. Fetal vibroacoustic stimulation for facilitation of tests of fetal wellbeing. Cochrane Database Sys Rev. 2013; (12):CD002963. [DOI:10.1002/14651858.CD002963.pub2]

8. Cunningham F, Leveno K, Bloom S, Spong CY, Dashe J. Williams obstetrics. 24th edition. New York: Mcgraw-hill; 2018.

9. Sambarey P, Bilagi DM. Non-stress test and vibroacoustic stimulation test in high-risk pregnancies and its relation to perinatal outcome. Int J Sci Study. 2016; 3(11):173-7.

10. Cunningham F, Hoffman B, Leveno $\mathrm{K}$, Bloom S, Spong CY, Dashe J. Williams Obstetrics. 25th Edition. Study Guide. New York: McGraw-Hill; 2018.

11. Naderi T, Nikian Y, Amin Zadeh F. Sensitivity and specificity of NST in cases with decrease of fetal movement and amniotic fluid volume. JBUMS. 2002; 4 (1) :7-10

12. Nazari S, Hatami E, Tabatabayee Chehr M, Bagheri M, Ghorbani M. Diagnostic value of non-stress test interpreted by smart interpretive software. J Midwifery Reproduc Health. 2018; 6(3):1384-9.

13. Esin S, Baser E, Cakir C, Ustun Tuncal GN, Kucukozkan T. Chocolate or orange juice for non- reactive non-stress test (NST) patterns: a randomized prospective controlled study. J Matern-Fet Neonat Med. 2013; 26(9):915-9. [DOI:10.3109/14767058.2013.766698] [PMID]

14. Küçükkelepçe DŞ, Taşhan ST. The effect of music on the results of a non-stress test: A non-randomized controlled clinical trial. Euro J Integrat Med. 2018; 18:8-12. [DOI:10.1016/j.eujim.2018.01.002]

15. Mirbagher Ajorpaz N, Aghajani M. The effects of music and Holy Quran on patients' anxiety and vital signs before abdominal surgery. Evid Base Care. 2011; 1(1):63-76.

16. Akbarzade M, Rafiee B, Asadi N, Zare N. The effect of maternal relaxation training on reactivity of nonstress test, Basal fetal heart rate, and number of fetal heart accelerations: a randomized controlled trial. Int J Commu-base Nurs Midwifery. 2015; 3(1):51. [DOI:10.17795/whb-23649]

17. Dolker HE, Basar F. The effect of music on the nonstress test and maternal anxiety. Complementary therapies in clinical practice. Complement Ther Clin Pract. 2019; 35:259-64. [DOI:10.1016/j.ctcp.2019.03.007] [PMID]

18. Kafalİ H, Derbent A, Keskİn E, Sİmavlİ S, Gözdemİr E. Effect of maternal anxiety and music on fetal movements and fetal heart rate patterns. J Matern-Fet Neonat Med. 2011; 24(3):461-4. [DOI:10.3109/14767058.2010.501122] [PMID]

19. Oh MO, Kim YJ, Baek CH, Kim JH, Park NM, Yu MJ, et al. Effect of music intervention on maternal anxiety and fetal heart rate pattern during non-stress test. J Korea Acad Nurs. 2016; 46(3):315-26. [DOI:10.4040/jkan.2016.46.3.315] [PMID]

20. Pirhadi M. The effect of vibroacoustic stimulation and music on fetal movement. Int J Ped. 2015; 3(5.1):903-8.

21. Khoshkholgh R, Keshavarz T, Moshfeghy Z, Akbarzadeh M, Asadi N, Zare N. Comparison of the effects of two auditory methods by mother and fetus on the results of non-stress test (baseline fetal heart rate and number of accelerations) in pregnant women: a randomized controlled trial. J Family Reproduc Health. 2016; 10(1):27.

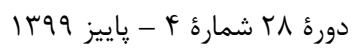

